\title{
Effect of feeding a reduced-starch diet with or without amylase addition on lactation performance in dairy cows
}

\author{
H. Gencoglu, ${ }^{*} \dagger$ R. D. Shaver, ${ }^{* 1}$ W. Steinberg,‡ J. Ensink, ${ }^{\star} \S$ L. F. Ferraretto, ${ }^{*}$ S. J. Bertics, ${ }^{*}$ J. C. Lopes, ${ }^{*}$ \\ and M. S. Akins* \\ *Department of Dairy Science, University of Wisconsin-Madison, 1675 Observatory Dr., Madison 53706 \\ †Department of Animal Nutrition and Nutritional Diseases, Faculty of Veterinary Medicine, University of Uludag, Bursa 16059, Turkey \\ fDSM Nutritional Products Research Center for Animal Nutrition \& Health, Basel 4002, Switzerland \\ §Wageningen University, Wageningen 6700, the Netherlands
}

\section{ABSTRACT}

The objective of this study was to determine lactation performance responses of high-producing dairy cows to a reduced-starch diet compared with a normal-starch diet and to the addition of exogenous amylase to the reduced-starch diet. Thirty-six multiparous Holstein cows $(51 \pm 22 \mathrm{DIM}$ and $643 \pm 49 \mathrm{~kg}$ of body weight at trial initiation) were randomly assigned to 1 of 3 treatments in a completely randomized design: a 3-wk covariate adjustment period during which the cows were fed the normal-starch diet, followed by a 12 -wk treatment period during which the cows were fed their assigned treatment diets. The normal-starch TMR did not contain exogenous amylase (NS-). The reducedstarch diets, formulated by partially replacing corn grain with soy hulls, were fed without (RS-) and with $(\mathrm{RS}+)$ exogenous amylase added to the TMR. Starch and NDF concentrations averaged 27.1 and 30.6\%, 21.8 and $36.6 \%$, and 20.7 and $36.6 \%$ (dry matter basis) for the NS-, RS-, and RS+ diets, respectively. Dry matter intake for cows fed the RS- diet was 2.4 and $3.2 \mathrm{~kg} / \mathrm{d}$ greater than for cows fed the NS- and RS+ diets, respectively. Intake of NDF ranged from 1.19 to $1.52 \%$ of body weight among the treatments, with the RS- diet being $28 \%$ greater than the NS- diet and $13 \%$ greater than the RS+ diet. Milk yield averaged $50.4 \mathrm{~kg} / \mathrm{d}$ and was unaffected by treatment. Fat-corrected milk yield was $2.9 \mathrm{~kg} / \mathrm{d}$ greater for cows fed the RS- diet than for cows fed the NS- diet. Body weight and body condition score measurements were unaffected by treatment. Fat, solids-, and energy-corrected milk feed conversions (kilograms/kilogram of DMI) were 12 to $13 \%$ greater for cows fed the RS+ diet than for cows fed the RSdiet. Dry matter and nutrient digestibilities were lowest for cows fed the NS- diet and greatest for cows fed the $\mathrm{RS}+$ diet, and were greater for cows fed the RS+ diet

Received August 25, 2009.

Accepted October 29, 2009

${ }^{1}$ Corresponding author: rdshaver@wisc.edu than for cows fed the RS- diet, with the exception of starch digestibility, which was similar. Greater conversion of feed to milk for dairy cows fed reduced-starch diets that include exogenous amylase may offer potential for improving economic performance.

Key words: amylase, lactating cow, soy hull, starch

\section{INTRODUCTION}

The optimum starch content of diets for lactating dairy cows is not well defined, but 24 to $26 \%$ starch (DM basis) has been suggested (Staples, 2007). Kaiser and Shaver (2006) and Bucholtz (2006), from surveys of high-producing commercial dairy herds in Wisconsin and Michigan, respectively, reported dietary starch concentrations ranging from 25 to $30 \%$ (DM basis). High corn prices have heightened the interest in feeding reduced-starch diets. Results from short-term dairy cattle feeding trials suggest that reduced-starch diets formulated by partially replacing corn grain in diets with high-fiber, low-starch byproduct feedstuffs may be feasible (Batajoo and Shaver, 1994; Stone, 1996; Ipharraguerre and Clark, 2003; Voelker and Allen, 2003a), but longer-term lactation trials and trials with higher producing cows are warranted.

Starch contributes approximately 50 and $75 \%$ of the energy value of corn silage and grain, respectively (calculated from NRC, 2001). Thus, improving corn starch utilization can reduce feed costs by reducing corn in diets or increase income by increasing milk production. Total tract digestibility of starch by dairy cows is highly variable, ranging from 70 to $100 \%$ (Firkins et al., 2001). Various feed-related factors influence the digestibility of corn starch by dairy cows; such factors include grain particle size; processing method; harvest and storage method; harvest maturity and moisture content and endosperm type; and corn silage maturity, chop length, kernel processing, and endosperm type (Nocek and Tamminga, 1991; Johnson et al., 1999; Firkins et al., 2001). 
Some exogenous enzymes are resistant to ruminal degradation (Hristov et al., 1998) and thus may offer potential for improving diet digestibility and animal performance. Klingerman et al. (2009) reported that adding exogenous amylase to a normal-starch diet $(26 \%$ of DM) increased milk yield by dairy cows; positive in vitro and in vivo digestibility responses to exogenous amylase were also observed. These results suggest that the addition of exogenous amylase to dairy cattle diets merits further study.

The objective of this study was to determine DMI, total tract digestibility, and lactation performance responses in high-producing dairy cows to 1) a reducedstarch diet compared with a normal-starch diet formulated by partially replacing corn grain with soy hulls, and 2) addition of exogenous amylase to the reducedstarch diet.

\section{MATERIALS AND METHODS}

Thirty-six multiparous Holstein cows $(51 \pm 22$ DIM and $643 \pm 49 \mathrm{~kg}$ of BW at trial initiation) were randomly assigned to 1 of 3 treatments in a completely randomized design: a 3 -wk covariate adjustment period during which cows were fed the normal-starch diet, followed by a 12 -wk treatment period during which cows were fed their assigned treatment diets. Ingredient composition of the experimental diets is provided in Table 1. The normal-starch TMR did not contain exogenous amylase (NS-). The reduced-starch diets were fed without (RS-) and with $(\mathbf{R S}+)$ the addition of exogenous amylase to the TMR. A liquid amylase formulation, Ronozyme RumiStar (lot \# AUN01024 and AUN01028) with an amylase activity of 240 kilo novo units (KNU)/g (DSM Nutritional Products, Basel, Switzerland; Novozymes, Bagsvaerd, Denmark) was used for this study. The targeted dosage of $300 \mathrm{KNU} / \mathrm{kg}$ of TMR DM was achieved by adding a mixture of 2.23 $\mathrm{mL}$ of the stock amylase solution $(1.25 \mathrm{~g} / \mathrm{mL})$ and 8.9 $\mathrm{mL}$ of water per kilogram of concentrate (as fed basis) by hand using a sprinkler can as the RS+ concentrate was being mixed in the TMR mixer. After mixing for 3 min, the forages were added and the TMR was allowed to mix for another $3 \mathrm{~min}$. Equivalent amounts of water with similar mixing procedures were used to prepare the NS- and RS- TMR. The RS+ TMR was prepared last to avoid mixer clean-out concerns related to the amylase treatment. The diluted amylase solution was prepared weekly and refrigerated between the daily applications. Samples of RS- and RS+ concentrate mixes were obtained following mixing with water or amylase solution, respectively, every $3 \mathrm{wk}$, stored at $-20^{\circ} \mathrm{C}$, and then sent to DSM Nutritional Products Analytical Services Center (Basel, Switzerland) for analysis of
Table 1. Ingredient composition of the diets

\begin{tabular}{lcc}
\hline Ingredient (\% DM) & Normal starch & Reduced starch \\
\hline Corn silage & 33.3 & 33.3 \\
Alfalfa silage & 16.7 & 16.7 \\
Dry ground shelled corn & 22.8 & 14.8 \\
Soy hulls & 3.6 & 12.7 \\
Soybean meal-48\% & 9.8 & 8.7 \\
Distillers dried grains & 11.0 & 11.0 \\
Energy Booster 100 & 0.59 & 0.59 \\
Calcium carbonate & 1.20 & 1.20 \\
Magnesium oxide $^{1}$ & 0.27 & 0.27 \\
Mg-K-S $^{2}$ & 0.11 & 0.11 \\
Trace mineral salt $^{3}$ & 0.45 & 0.45 \\
Vitamin premix $^{4}$ & 0.18 & 0.18 \\
\hline
\end{tabular}

${ }^{1}$ Minimum $98 \%$ total fatty acids (MSC Company, Dundee, IL).

${ }^{2}$ Contains $11 \% \mathrm{Mg}, 18 \% \mathrm{~K}$, and $22 \% \mathrm{~S}$ (Dynamate; The Mosaic Co., Plymouth, MN).

${ }^{3}$ Contains $88 \% \mathrm{NaCl}, 0.002 \% \mathrm{Co}, 0.2 \% \mathrm{Cu}, 0.012 \% \mathrm{I}, 0.18 \% \mathrm{Fe}, 0.8 \%$ $\mathrm{Mn}, 0.006 \%$ Se, and $1.4 \% \mathrm{Zn}$.

${ }^{4}$ Contains $3,300,000 \mathrm{IU} / \mathrm{kg}$ of vitamin A, 1,100,000 IU $/ \mathrm{kg}$ of vitamin $\mathrm{D}$, and $11,000 \mathrm{IU} / \mathrm{kg}$ of vitamin $\mathrm{E}$.

amylase activity (Jung and Vogel, 2008). Determined amylase activities for the RS+ and RS- concentrates were $664.1 \pm 81.1$ and $2.3 \pm 3.4 \mathrm{KNU} / \mathrm{kg}$ (as fed basis), respectively.

The animal research was conducted under an approved protocol by the Research Animal and Resource Center of the College of Agricultural and Life Sciences at the University of Wisconsin-Madison. The DIM at trial initiation for cows fed the NS-, RS-, and RS+ diets were $54 \pm 24,51 \pm 20$, and $50 \pm 23$, respectively. Injections with bST (Posilac, Monsanto Company, St. Louis, MO) were done every $14 \mathrm{~d}$ beginning the week before the start of the covariate period so that a weekly injection occurred during the first week of the treatment period for all cows. Cows were individually fed the TMR twice daily in tie-stalls for $5 \%$ refusal, and DMI was measured on individual cows throughout the 15 -wk trial. Body weight and BCS (1-5 in 0.25 increments; Wildman et al., 1982) were recorded weekly throughout the 15 -wk trial. Body weight change was calculated as the difference between the BW in the last week of the trial and the BW in the first week of the treatment period. Milk yield was recorded daily on individual cows milked twice daily throughout the 15 -wk trial. Milk samples were obtained weekly from a.m. and p.m. milkings from all cows on the same 2 consecutive days throughout the 15 -wk trial and were analyzed for fat, true protein, lactose, and MUN concentrations by infrared analysis (AgSource Milk Analysis Laboratory, Menomonie, WI) using a Foss FT6000 (Foss Electric, Hillerød, Denmark) with average daily yields of fat, protein, and lactose calculated from these data for each week. Yields of FCM, SCM, and ECM were calculated according to NRC (2001) equations. Actual milk and 
FCM, SCM, and ECM feed conversions were calculated by week using average daily yield and DMI data. Estimated diet energy concentrations were calculated by adding the megacalories of $\mathrm{NE}_{\mathrm{L}}$ from milk production, required for maintenance, and in BW change (NRC, 2001) and then dividing the sum by DMI.

Samples of TMR were obtained weekly and composited by 3 -wk periods, and the composites were analyzed for DM, OM, CP, NDF, starch, sugars, ether extract, and particle size. Corn silage was sampled weekly and composited by 3 -wk periods, and the composites were analyzed for DM, OM, CP, NDF, starch, particle size (Kononoff et al., 2003), and processing score (Ferreira and Mertens, 2005). The concentrate mixtures, corn grain, and alfalfa silage were sampled weekly and composited by 3 -wk periods, and the composites were analyzed for DM, OM, CP, NDF, and starch. Particle size of alfalfa silage and TMR composite samples was determined as described by Kononoff et al. (2003). Particle size of the concentrate mixtures and corn grain composite samples was determined at Cumberland Valley Analytical Services Inc. (Maugansville, MD) by dry sieving using Tyler Ro-Tap Shaker Model RX-29 (Mentor, OH) and sieves with 2,380-, 1,680-, 1,191-, 841-, 594-, 420-, 297-, 212-, 150-, 103-, 73-, 53-, and $37-\mu \mathrm{m}$ apertures plus a bottom pan with mean particle size calculated using a log normal distribution (Baker and Herrman, 2002). Ruminal in vitro NDF digestibility $(30 \mathrm{~h})$ on alfalfa and corn silage samples and starch digestibility $(7 \mathrm{~h})$ on corn grain and silage samples were determined at Cumberland Valley Analytical Services Inc. as described by Lopes et al. (2009).

Total tract nutrient (DM, OM, CP, NDF, and starch) digestibilities were determined using 120 -h indigestibile NDF as an internal marker. Six fecal grab samples were collected from each cow at 8-h intervals covering each 4-h clock period over 3 consecutive days during wk 8 of the treatment period. Ort samples were collected for each cow daily during the fecal sampling period. Treatment TMR samples were collected daily during the fecal sampling period. Treatment TMR, fecal, and ort samples were composited by period (TMR samples) or cow within period (ort and fecal samples) and the composite samples were analyzed for DM, OM, CP, NDF, starch, and 120-h indigestible NDF. Duplicate TMR, ort, and fecal composite samples were incubated for 120 $\mathrm{h}$ in rumen fluid using the in vitro procedure described by Goeser and Combs (2009) to determine 120-h indigestible NDF. Total tract nutrient digestibilities were calculated from 120-h indigestible NDF and nutrient concentrations in the orts-adjusted diet and feces.

All samples for determination of nutrient composition were dried at $60^{\circ} \mathrm{C}$ for $48 \mathrm{~h}$ in a forced-air oven to determine DM content, ground to pass a 1-mm Wiley mill (Arthur H. Thomas, Philadelphia, PA) screen, and composited before being sent to Dairyland Laboratories Inc. (Arcadia, WI) for analysis of $\mathrm{OM}$ (ashing at $600^{\circ} \mathrm{C}$ for $2 \mathrm{~h}$ ), CP and ether extract (AOAC, 1995), NDF using $\alpha$-amylase and sodium sulfite (Van Soest et al., 1991), starch (Bach Knudsen, 1997; YSI Biochemistry Analyzer, YSI Inc., Yellow Springs, $\mathrm{OH}$ ), and sugars (Hall et al., 1999).

Following measurement of refusal amounts on the last day of the experiment, cows were fed their respective treatment diets. Feed was withdrawn $12 \mathrm{~h}$ before the next day's feeding, and blood samples were collected into Vacutainer tubes (Becton Dickson, Franklin Lakes, $\mathrm{NJ}$ ) from the coccygeal vein immediately before and 2 $\mathrm{h}$ after that feeding. Blood samples were centrifuged at $2,050 \times g$ at $20^{\circ} \mathrm{C}$ for $20 \mathrm{~min}$; serum was stored at $-20^{\circ} \mathrm{C}$ until analyzed for insulin concentration (Porcine Insulin RIA Kit PI 12K, Linco Research Inc., St. Charles, MO).

Lactation performance data were analyzed as a completely randomized design with the data from the preliminary period as a covariate using PROC MIXED (SAS Institute, 2004), with week of treatment as repeated measures using the first-order autoregressive covariance structure that provided the best fit according to Sawa's Bayesian information criterion. The model included treatment, week, and treatment by week interaction as fixed effects and cow within treatment as a random effect. There were no covariate or repeated measures effects included in the analysis of nutrient digestibility, serum insulin, BW change, or estimated diet energy concentration data. Degrees of freedom were calculated using the Kenward-Roger option. Means were determined using the least squares means statement, and treatment means were compared using the PDIFF option. Statistical significance and trends were considered at $P \leq 0.05$ and $P \geq 0.06$ to $P<0.10$, respectively.

\section{RESULTS AND DISCUSSION}

The nutrient composition and particle size of forages and concentrates fed during the trial are presented in Table 2. The corn and alfalfa silages were of good quality (NRC, 2001). Normal- and reduced-starch concentrates were of similar CP content and differed by 12.4 percentage units for starch content. Diet nutrient composition (orts adjusted) and particle size are presented in Table 3. The NS- diet was similar to the RS diets in $\mathrm{CP}$ content, but differed by 5.8 and 6.0 percentage units on average for starch and NDF contents, respectively. This was related to the partial replacement of dry shelled corn (8 percentage units less corn DM) with soy hulls in the RS diets. The RS diets were on average 
Table 2. Nutrient composition and particle size of corn silage, alfalfa silage, and concentrates

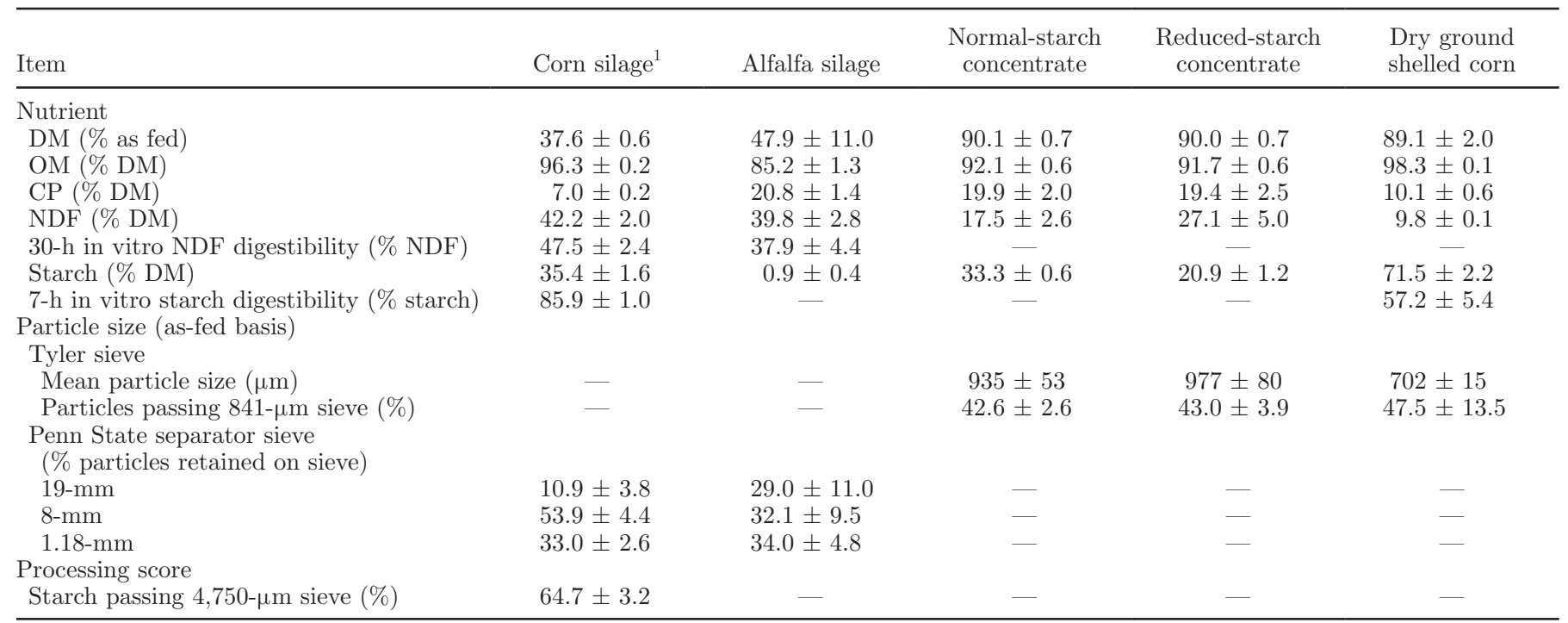

${ }^{1}$ Gehl Model 1085 forage harvester (West Bend, WI) fitted with kernel processor (1.9-cm theoretical length of cut; 2-mm roll clearance).

5.3 percentage units lower in NFC than the NS- diet. Measurements for other nutrient concentrations and particle size were similar across the 3 diets.

Treatment effects on covariate-adjusted least squares means for DM and nutrient intakes are presented in Table 4. The DMI for cows fed the RS- diet was 2.4 and $3.2 \mathrm{~kg} / \mathrm{d}$ greater than for cows fed the NS- diet $(P<0.02)$ and the RS+ diet $(P<0.01)$, respectively. A similar treatment effect was observed for DMI, expressed as a percentage of BW. Stone (1996) reported a tendency for $1.9 \mathrm{~kg} / \mathrm{d}$ greater DMI by lactating dairy cows when soy hulls partially replaced high-moisture corn (14 percentage units less corn DM) in diets fed to multiparous cows, but DMI in the other trials reviewed by Ipharraguerre and Clark (2003) was not increased
( $P>0.10)$ by partially replacing grains with soy hulls. Beckman and Weiss (2005) reported greater DMI for lactating dairy cows fed reduced-starch diets with a mixture of soy hulls and cottonseed hulls partially replacing dry ground shelled corn (6 percentage units less corn DM). Reduced ruminal propionate concentration (Allen, 1997) may have increased meal size and thus DMI (Allen et al., 2009) for the RS- diet compared with the NS- or RS+ diets. Addition of exogenous amylase to normal-starch (26-27\%) diets has been found to increase DMI and milk yield (Klingerman et al., 2009) or increase milk yield but not DMI (Tricarico et al., 2005). To our knowledge, this is the first study on the addition of exogenous amylases to reduced-starch diets for determining effects on DMI and milk yield of

Table 3. Diet nutrient composition (orts adjusted) and particle size $\mathrm{e}^{1}$

\begin{tabular}{|c|c|c|c|}
\hline Item & NS- & $\mathrm{RS}_{-}$ & $\mathrm{RS}+$ \\
\hline \multicolumn{4}{|c|}{ Nutrient (\% DM unless noted) } \\
\hline $\mathrm{DM}(\%$ as fed $)$ & $57.0 \pm 5.1$ & $56.0 \pm 3.4$ & $55.7 \pm 3.0$ \\
\hline $\mathrm{OM}$ & $91.9 \pm 3.0$ & $91.9 \pm 3.0$ & $92.0 \pm 3.0$ \\
\hline $\mathrm{CP}$ & $16.6 \pm 0.1$ & $16.7 \pm 0.5$ & $16.7 \pm 0.7$ \\
\hline Ether extract & $4.2 \pm 0.5$ & $4.3 \pm 0.4$ & $4.2 \pm 0.4$ \\
\hline NDF & $30.6 \pm 1.3$ & $36.6 \pm 1.6$ & $36.6 \pm 2.1$ \\
\hline $\mathrm{NFC}$ & $42.7 \pm 1.7$ & $37.2 \pm 1.2$ & $37.6 \pm 0.8$ \\
\hline Starch & $27.1 \pm 1.4$ & $21.8 \pm 1.0$ & $20.7 \pm 1.1$ \\
\hline Sugars & $3.9 \pm 0.8$ & $3.2 \pm 0.3$ & $3.9 \pm 0.3$ \\
\hline $\mathrm{TDN}_{1 \mathrm{x}}^{2}$ & $74.3 \pm 1.4$ & $74.5 \pm 1.1$ & $74.5 \pm 1.1$ \\
\hline \multicolumn{4}{|c|}{ Penn State separator sieve ( $\%$ as fed retained) } \\
\hline $19-\mathrm{mm}$ & $7.6 \pm 2.1$ & $6.8 \pm 1.5$ & $7.4 \pm 1.8$ \\
\hline $8-\mathrm{mm}$ & $30.4 \pm 5.1$ & $30.0 \pm 3.6$ & $30.3 \pm 5.4$ \\
\hline $1.18-\mathrm{mm}$ & $41.3 \pm 1.9$ & $42.1 \pm 1.9$ & $42.1 \pm 2.3$ \\
\hline
\end{tabular}




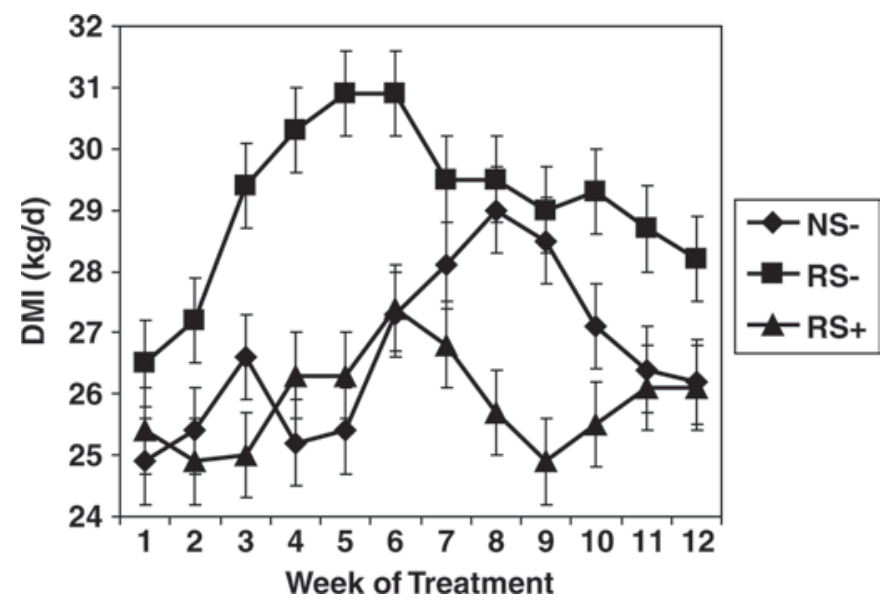

Figure 1. Effect of treatment on DMI $(\mathrm{kg} / \mathrm{d})$ covariate-adjusted least squares means by week of treatment. Treatments were normalstarch diet with no amylase added to TMR (NS-), reduced-starch diet with no amylase added to TMR (RS-), and reduced-starch diet with amylase added to TMR (RS+). Week and week $\times$ treatment interaction effects $(P<0.01)$.

dairy cows, and more research is warranted. Covariateadjusted least squares means by week of treatment for DMI (kilograms/day) are presented in Figure 1; there were week and week $x$ treatment interaction effects $(P<0.01)$. We have no explanation for the observed interaction. The increase in DMI for cows fed the RSdiet compared with cows fed the NS- diet was greatest during wk 3 to 6 of treatment. Differences in DMI between cows fed the RS- diet and cows fed the RS+ diet were slightly more consistent across wk 3 to 12 of the treatment period.

Treatment effects on OM and CP intakes were similar to those observed for DMI. Intake of NDF was greater $(P<0.01)$ and intake of starch was lower $(P<0.01)$ for cows fed the RS- diet than for cows fed the NS- diet. Intakes of both NDF $(P<0.01)$ and starch $(P<0.01)$ were greater for cows fed the RS- diet than for cows fed the RS+ diet and related to the greater DMI observed for the RS- diet at similar diet nutrient composition. A similar treatment effect was observed for NDF intake expressed as a percentage of $\mathrm{BW}$, which ranged from 1.19 to $1.52 \%$ of BW among the treatments, with the RS- diet being $28 \%$ greater than the NS- diet and $13 \%$ greater than the RS+ diet. Mertens (1987) reported that daily NDF intake was $1.2 \pm 0.1 \%$ of $\mathrm{BW}$ for diets that resulted in maximum FCM production and suggested that this NDF intake constant could be used in models to predict DMI of diets containing concentrate mixtures based on ground corn and soybean meal when the forage base consisted of alfalfa, corn silage, and coolseason grasses. Intake of NDF was within that range for the NS- diet. When Batajoo and Shaver (1994) fed lactating cows diets containing 33, 29, 24, and $18 \%$ starch using wheat middlings, dried brewers grains, and soy hulls to partially replace dry shelled corn and soybean meal, the resulting NDF intakes were 1.14, 1.30, 1.45, and $1.62 \%$ of BW. Although their normal- and highstarch diets fell within the range suggested by Mertens (1987), the feeding of reduced-starch diets resulted in higher NDF intakes expressed as a percentage of BW in agreement with our findings herein. Clearly, dairy cows can increase their NDF fill when fed diets containing nonforage fiber sources, presumably in response to the inherently high fiber digestibility and rapid passage rate found for many of these ingredients (Firkins, 1997), including soy hulls (Firkins, 1997; Ipharraguerre and Clark, 2003).

Treatment effects on covariate-adjusted least squares means for lactation performance measurements are presented in Table 5. Milk yield was unaffected by treatment $(P>0.10)$ and averaged $50.4 \mathrm{~kg} / \mathrm{d}$. This observation is in agreement with the review of Ipharraguerre and Clark (2003) regarding the partial replacement of grains with soy hulls. Furthermore, feeding reduced-starch diets did not affect milk yield in the tri-

Table 4. Effect of treatment on covariate-adjusted least squares means for DM and nutrient intakes ${ }^{1,2}$

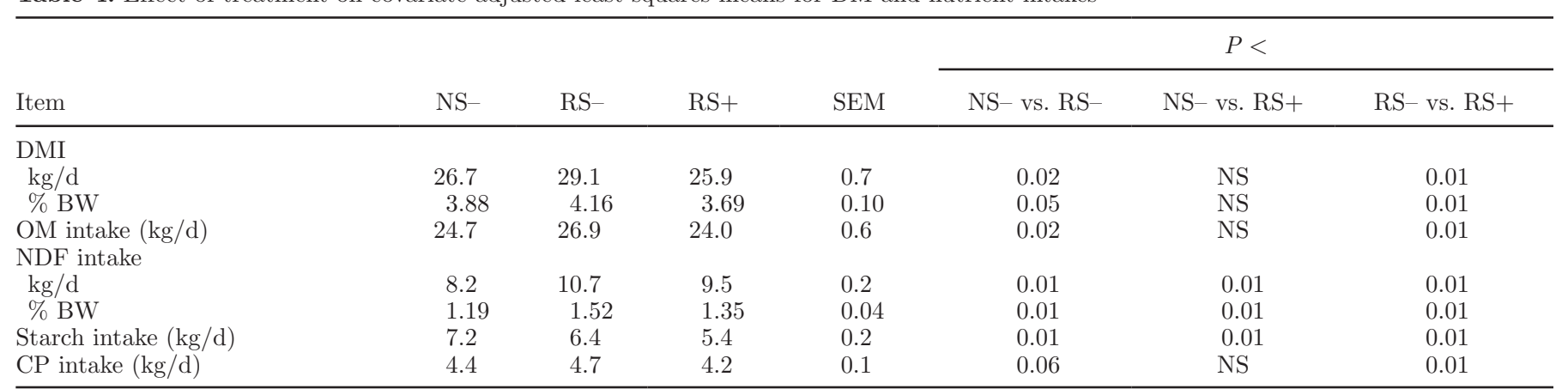

${ }^{1}$ Treatments were normal-starch diet with no amylase added to TMR (NS-), reduced-starch diet with no amylase added to TMR (RS-), and reduced-starch diet with amylase added to TMR (RS+).

${ }^{2}$ Week and week $\times$ treatment interaction effects $(P<0.01)$ for all parameters. 
Table 5. Effect of treatment on covariate-adjusted least squares means for lactation performance ${ }^{1,2}$

\begin{tabular}{|c|c|c|c|c|c|c|c|}
\hline Item & NS- & RS- & $\mathrm{RS}+$ & SEM & \multicolumn{3}{|c|}{$P<$} \\
\hline \multicolumn{8}{|l|}{ Yield } \\
\hline $3.5 \%$ FCM $(\mathrm{kg} / \mathrm{d})$ & 46.2 & 49.1 & 48.2 & 0.8 & 0.02 & 0.10 & NS \\
\hline $\mathrm{SCM}^{3}(\mathrm{~kg} / \mathrm{d})$ & 43.0 & 45.1 & 44.5 & 0.7 & 0.03 & 0.10 & NS \\
\hline $\mathrm{ECM}^{3}(\mathrm{~kg} / \mathrm{d})$ & 46.4 & 48.7 & 48.1 & 0.7 & 0.04 & 0.10 & NS \\
\hline $\mathrm{kg} / \mathrm{d}$ & 1.52 & 1.68 & 1.63 & 0.04 & 0.02 & 0.09 & NS \\
\hline \multicolumn{8}{|l|}{ Protein } \\
\hline$\%$ & 3.07 & 2.99 & 3.06 & 0.03 & 0.06 & NS & 0.10 \\
\hline $\mathrm{kg} / \mathrm{d}$ & 1.52 & 1.52 & 1.54 & 0.03 & NS & NS & NS \\
\hline \multicolumn{8}{|l|}{ Lactose } \\
\hline$\%$ & 4.93 & 4.93 & 4.92 & 0.03 & NS & NS & NS \\
\hline
\end{tabular}

${ }^{1}$ Treatments were normal-starch diet with no amylase added to TMR (NS-), reduced-starch diet with no amylase added to TMR (RS-), and reduced-starch diet with amylase added to TMR (RS+).

${ }^{2}$ Week effect $(P<0.01)$ for all parameters.

${ }^{3}$ Calculated according to NRC (2001) equations.

${ }^{4}$ Week $\times$ treatment interaction $(P<0.01)$.

als of Batajoo and Shaver (1994), Beckman and Weiss (2005), and Dann et al. (2008). Addition of exogenous amylases to normal-starch diets increased milk yield in the trials of Tricarico et al. (2005), Harrison and Tricarico (2007), and Klingerman et al. (2009). Yield of FCM was $2.9 \mathrm{~kg} / \mathrm{d}$ greater $(P<0.02)$ for cows fed the RS- diet than for cows fed the NS- diet and tended to be $2.0 \mathrm{~kg} / \mathrm{d}$ greater $(P<0.10)$ for cows fed the $\mathrm{RS}+$ diet than for cows fed the NS- diet. The yield of FCM was not affected by the partial replacement of grains with soy hulls (Ipharraguerre and Clark, 2003) or by feeding reduced-starch diets (Batajoo and Shaver, 1994; Dann et al., 2008). Addition of exogenous amylases to normal-starch diets increased FCM yield in the trials of Tricarico et al. (2005) and Klingerman et al. (2009). Similar treatment effects as those observed for FCM yield were observed for SCM, ECM, and milk fat yields. The SCM and ECM yields were unaffected by feeding reduced-starch diets in the trials of Dann et al. (2008) and Beckman and Weiss (2005), respectively. The yield of ECM tended to be greater $(P<0.10)$ for cows fed a normal-starch diet with exogenous amylase added (Tricarico et al., 2005).

Milk fat content averaged 3.30\% for the RS diets compared with $3.08 \%$ for the NS- diet; only the comparison between the NS- and RS- diets approached a trend $(P<0.12)$. Ipharraguerre and Clark $(2003)$ concluded from their review that the partial replacement of grains with soy hulls was effective for maintaining or slightly increasing milk fat content. Increased milk fat content in response to feeding cows reduced-starch diets was reported by Batajoo and Shaver (1994) and Beckman and Weiss (2005). In our trial, the increase in milk fat content for cows fed the RS- diet compared with the NS- diet was likely related to effects of the greater intake of NDF and lower intake of starch on greater ruminal acetate concentrations and lower propionate concentrations (Allen, 1997) for the RS- diet. Although ruminal VFA were not measured in our study, these responses to feeding cows reduced-starch diets were reported by Ipharraguerre et al. (2002a) using soy hulls and by Batajoo and Shaver (1994) and Beckman and Weiss (2005) using a mixtures of nonforage fiber sources. Addition of exogenous amylases to normal-starch diets did not affect milk fat content in the trials of Tricarico et al. (2005), Harrison and Tricarico (2007), and Klingerman et al. (2009) or for our RS+ versus RS- diet comparison. Greater ruminal starch digestibility resulting from exogenous amylase addition (Klingerman et al., 2009) could reduce ruminal $\mathrm{pH}$ and acetate molar proportions and increase propionate molar proportions, possibly resulting in lower milk fat content (Allen, 1997). However, dietary exogenous amylase addition has been found to increase ruminal acetate and butyrate molar proportions and decrease propionate molar proportions (Tricarico et al., 2007) which could explain the similar milk fat contents for cows fed the RS- diet and the RS+ diet in our study. Furthermore, addition of exogenous amylases to normal-starch diets did not affect ruminal starch digestibility in the trial of Tricarico et al. (2005). Tricarico et al. (2007) suggested that the increases in ruminal acetate and butyrate molar proportions from 
the dietary addition of exogenous amylase were the result of hydrolysis of starch to maltodextrins that can be used by amylolytic and nonamylolytic bacteria in cross-feeding mechanisms that modify VFA production. This premise requires further research.

Milk protein content tended to be greater for cows fed the NS- $\operatorname{diet}(3.07$ versus $2.99 \% ; P<0.06)$ and the RS+ diet $(3.06$ versus $2.99 \% ; P<0.10)$ than for cows fed the RS- diet. The review of Ipharraguerre and Clark (2003) found that the partial replacement of grains with soy hulls depressed milk protein content in agreement with our findings. Furthermore, the feeding of reduced-starch diets reduced milk protein content in the trial of Batajoo and Shaver (1994). In our trial, the decrease in milk protein content for cows fed the RS- diet compared with the NS- diet was possibly related to the lower intake of starch reducing ruminal microbial protein production (NRC, 2001) for the RSdiet. Addition of exogenous amylases to normal-starch diets did not affect milk protein content in the trials of Tricarico et al. (2005), Harrison and Tricarico (2007), and Klingerman et al. (2009). Greater milk protein content for cows fed the RS+ diet relative to the RS- diet could have resulted from greater ruminal starch digestibility increasing microbial protein production (NRC, 2001). Values for MUN ranged from 11.1 to $13.0 \mathrm{mg} /$ $\mathrm{dL}$ across the treatments and was lowest for cows fed the NS- diet and greatest for cows fed the RS- diet $(P<0.01)$. Reduced MUN coupled with greater milk protein concentrations for the RS+ diet than the RSdiet seems to agree with the suggestion of Voelker and Allen (2003b) that lower ruminal amylase activity for a reduced starch diet may reduce rate of starch digestion and thus microbial protein production, which may have been enhanced by addition of exogenous amylase to the RS diet. Intraruminal dosing with starch reduced ruminal ammonia concentrations in lactating dairy cows more than dosing with NDF (Hristov et al., 2005), which could explain the greater MUN for the RS- diet than the NS- diet. However, the partial replacement of dry ground shelled corn in a control diet with 10, 20, 30 , or $40 \%$ soy hulls (DM basis) did not affect MUN (Ipharraguerre et al., 2002b). Greater ruminal starch digestibility could explain the lower MUN for the RS+ diet than the RS- diet (NRC, 2001). However, addition of exogenous amylases to normal-starch diets did not affect MUN in the trials of Tricarico et al. (2005) and Klingerman et al. (2009). Least squares means by week of treatment for MUN are presented in Figure 2; there were week and week $\times$ treatment interaction effects $(P$ $<0.01$ ). Based on the weekly MUN results, it appears that 2 wk were required for adaptation to the RS diets. Evidence for a 2-wk adaptation period based on MUN data could not be found in the literature and further

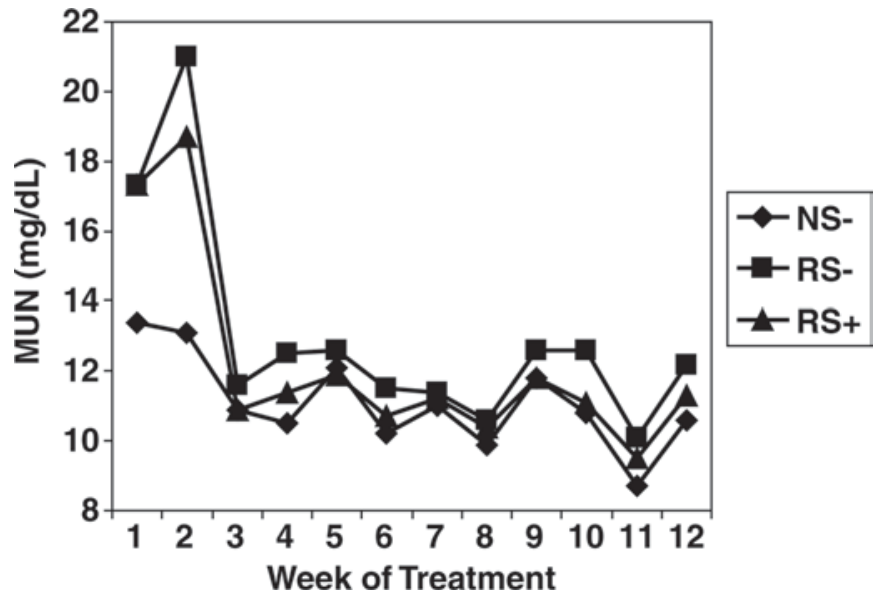

Figure 2. Effect of treatment on MUN (mg/dL) covariate-adjusted least squares means by week of treatment. Treatments were normalstarch diet with no amylase added to TMR (NS-), reduced-starch diet with no amylase added to TMR (RS-), and reduced-starch diet with amylase added to TMR (RS+). Week and week $\times$ treatment interaction effects $(P<0.01 ;$ SEM $=0.2)$.

research is warranted. Treatment differences were relatively consistent across wk 3 to 12 of the treatment period.

Treatment effects on covariate-adjusted least squares means for BW, BW change, BCS, feed conversion, and estimated diet energy concentrations are presented in Table 6. Body weight, BW change, and BCS were unaffected by treatment $(P>0.10)$. Feed conversion (kilograms of milk/kilograms of DMI) was $12 \%$ greater $(P$ $<0.01)$ for cows fed the RS+ diet than for cows fed the RS- diet and tended to be greater $(P<0.06)$ for cows fed the NS- diet than for cows fed the RS- diet. Least squares means by week of treatment for feed conversion (kilograms of milk/kilogram of DMI) are presented in Figure 3 ; there were week $(P<0.01)$ and week $\times$ treatment interaction $(P<0.05)$ effects. The difference between the RS+ and RS- diets was consistent throughout most of the treatment period. Feed conversion for FCM (kilograms of $3.5 \% \mathrm{FCM} /$ kilogram of DMI) was $12 \%$ greater $(P<0.02)$ for cows fed the RS+ diet than for cows fed the RS- diet and tended to be $7 \%$ greater $(P$ $<0.10)$ for cows fed the RS+ diet than for cows fed the NS- diet. Similar treatment effects as those observed for FCM feed conversion were also observed for SCM and ECM feed conversions. Estimated diet energy content (megacalories of $\mathrm{NE}_{\mathrm{L}}$ / kilogram of $\mathrm{DM}$ ), calculated using ECM, BW, BW change, and DMI data, was $12 \%$ greater $(P<0.02)$ for cows fed the RS+ diet than for cows fed the RS- diet and tended to be $8 \%$ greater $(P$ $<0.10)$ for cows fed the RS+ diet than for cows fed the NS- diet. The literature regarding partial replacement of grains with soy hulls, feeding reduced-starch diets, and addition of exogenous amylase to diets is 


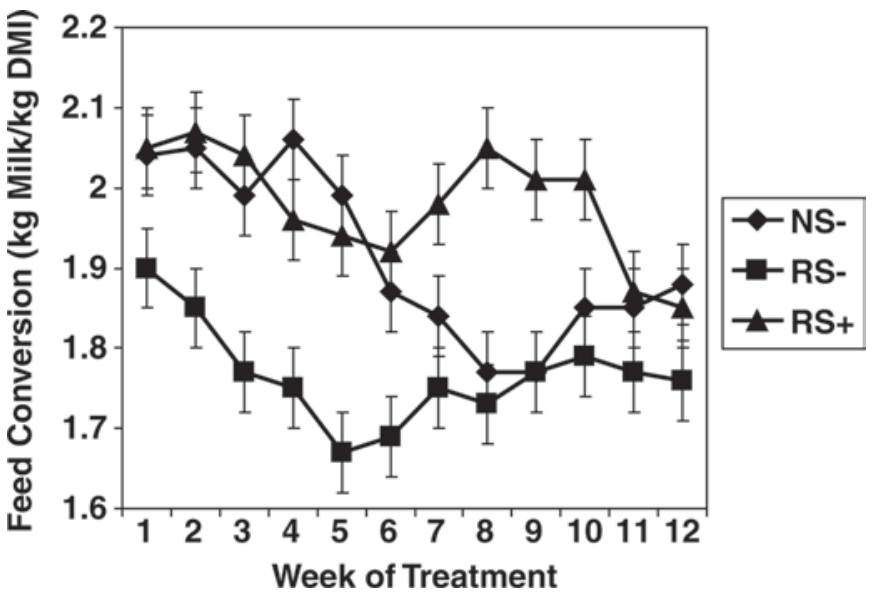

Figure 3. Effect of treatment on feed conversion $(\mathrm{kg}$ of milk $/ \mathrm{kg}$ of DMI) covariate-adjusted least squares means by week of treatment Treatments were normal-starch diet with no amylase added to TMR (NS-), reduced-starch diet with no amylase added to TMR (RS-), and reduced-starch diet with amylase added to TMR $(\mathrm{RS}+)$. Week $(P<$ $0.01)$ and week $\times$ treatment interaction $(P<0.05)$ effects.

largely comprised of short-term switchback trials where measurements of energy utilization were not performed. In view of our observations regarding energy utilization for these diets, more research on continuous lactation is warranted.

Treatment effects on least squares means for apparent total tract nutrient digestibilities and serum insulin concentrations are presented in Table 7. Digestibility measurements were taken during wk 8 of the treatment period, and the DMI data for this week are provided in Figure 1. Dry matter digestibility ranged from 66.6 to $74.7 \%$ across the treatments and was lowest for cows fed the NS- diet and greatest for cows fed the RS+ diet $(P$ $<0.01)$. Similar treatment effects as those observed for the NS- diet versus the RS+ diet comparison for DM digestibility were also observed for that comparison for $\mathrm{OM}, \mathrm{CP}, \mathrm{NDF}$, and starch digestibilities. Dry matter and nutrient digestibilities were greater $(P<0.01$ to $P<0.05)$ for cows fed the RS+ diet than for cows fed the RS- diet, with the exception of starch digestibility, which was similar $(P>0.10)$.

The observed greater apparent total tract nutrient digestibilities for reduced-starch diets concurs with the review of Firkins (1997) and was likely caused by reduced negative associate effects of starch on ruminal fermentation (Firkins, 1997). Greater apparent total tract NDF digestibility for cows fed the RS- diet than for cows fed the NS- diet could also be partially explained by the inherently high fiber digestibility of soy hulls (Firkins, 1997). The observed effects of the dietary addition of exogenous amylase on apparent total tract nutrient digestibilities were similar to those reported by Klingerman et al. (2009) and tend to support the ruminal cross-feeding hypothesis of Tricarico et al. (2007) that was described earlier. There are several possible explanations for the lack of difference in starch digestibility when exogenous amylase was added to the reduced-starch diet: 1) starch digestibility was not affected ruminally (Tricarico et al., 2005) or postruminally, 2) starch digestibility was increased ruminally (Klingerman et al., 2009), but postruminal compensatory starch digestion (Taylor and Allen, 2005) resulted in similar total tract starch digestibilities for the 2 treatments, and 3) starch digestibility was increased ruminally, but hindgut fermentation (Firkins,

Table 6. Effect of treatment on covariate-adjusted least squares means for BW, BW change, BCS, feed conversion, and estimated diet energy concentrations $^{1}$

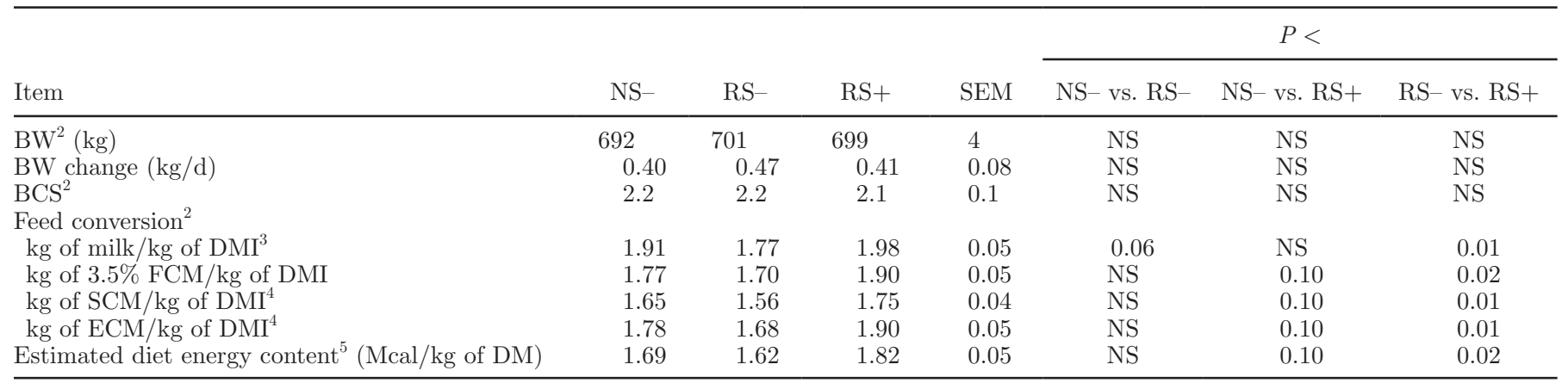

${ }^{1}$ Treatments were normal-starch diet with no amylase added to TMR (NS-), reduced-starch diet with no amylase added to TMR (RS-), and reduced-starch diet with amylase added to TMR (RS+).

${ }^{2}$ Week effect $(P<0.01)$.

${ }^{3}$ Week $\times$ treatment interaction $(P<0.05)$.

${ }^{4}$ Calculated according to NRC (2001) equations.

${ }^{5}$ Calculated by adding the Mcal of $\mathrm{NE}_{\mathrm{L}}$ from milk production, required for maintenance, and in BW change (NRC, 2001) and then dividing the sum by DMI. 
Table 7. Effect of treatment on least squares means for apparent total tract nutrient digestibilities and serum insulin concentrations ${ }^{1,2}$

\begin{tabular}{|c|c|c|c|c|c|c|c|}
\hline Item & NS- & $\mathrm{RS}_{-}$ & $\mathrm{RS}+$ & SEM & \multicolumn{3}{|c|}{$P<$} \\
\hline \multicolumn{8}{|l|}{ Digestibility (\%) } \\
\hline $\mathrm{OM}$ & 69.2 & 73.1 & 76.6 & 0.7 & 0.01 & 0.01 & 0.01 \\
\hline $\mathrm{CP}$ & 64.8 & 68.8 & 73.0 & 1.0 & 0.01 & 0.01 & 0.01 \\
\hline NDF & 39.4 & 54.1 & 57.8 & 1.3 & 0.01 & 0.01 & 0.05 \\
\hline \multicolumn{8}{|c|}{$\operatorname{Serum~insulin~}^{3}(\mu \mathrm{IU} / \mathrm{mL})$} \\
\hline Prefeeding & 4.32 & 4.83 & 2.90 & 0.7 & NS & NS & 0.05 \\
\hline $2 \mathrm{~h}$ postfeeding & 9.37 & 10.47 & 10.73 & 1.3 & NS & NS & NS \\
\hline
\end{tabular}

${ }^{1}$ Treatments were normal-starch diet with no amylase added to TMR (NS-), reduced-starch diet with no amylase added to TMR (RS-), and reduced-starch diet with amylase added to TMR (RS+).

${ }^{2}$ Determined using 120 -h indigestible NDF as an internal marker.

${ }^{3}$ Samples obtained immediately before feeding and $2 \mathrm{~h}$ postfeeding following a 12-h feed withdrawal.

1997) resulted in similar total tract starch digestibilities for the 2 treatments. Clearly, more research is needed regarding the mode of action for effects of the dietary addition of exogenous amylase on nutrient digestion.

Serum insulin concentrations for samples obtained 12 $\mathrm{h}$ after feed withdrawal and immediately before feeding were lower $(P<0.05)$ for cows fed the RS+ diet than for cows fed the RS- diet. Other than lower nutrient intakes for cows fed the RS+ diet than cows fed the RS- diet, we have no explanation for this finding. At 2 $\mathrm{h}$ post-feeding, serum insulin concentrations were unaffected by treatment $(P>0.10)$. Either the reduced DMI observed for cows fed the NS- diet compared with the RS- diet cannot be explained based on an increased insulin-related depression in feed intake (Bradford and Allen, 2007), or a single time point post-feeding was not sufficient to assess differences in serum insulin concentrations between treatments. Alternatively, differences in ruminal propionate concentrations may have been sufficient to alter meal patterns and thus DMI (Allen et al., 2009), but not serum insulin concentrations.

\section{CONCLUSIONS}

Feeding a reduced-starch diet formulated by partially replacing corn grain with soy hulls compared with a normal-starch diet, without addition of exogenous amylase to either diet, resulted in greater intakes of DM, $\mathrm{OM}, \mathrm{NDF}$, and $\mathrm{CP}$ but lower starch intake; greater apparent total tract nutrient digestibilities; and greater FCM, SCM, and ECM yields. Addition of exogenous amylase to the reduced-starch diet resulted in lower $\mathrm{DM}$ and nutrient intakes; greater apparent total tract nutrient digestibilities (except for starch, which was similar); lower MUN; and greater milk, FCM, SCM, and ECM feed conversions. The greater conversion of feed to milk for dairy cows fed reduced-starch diets with inclusion of exogenous amylase may offer potential for improving economic performance, depending on diet and additive costs.

\section{ACKNOWLEDGMENTS}

Appreciation is extended to DSM Nutritional Products (Basel, Switzerland) for partial funding for this project, Mike Peters and Jerry Guenther and the staff at the University of Wisconsin Dairy Cattle Center (Madison, WI) for animal care and trial management, Katie Hackbart in the laboratory of Milo Wiltbank (University of Wisconsin-Madison) for determination of serum insulin concentrations, and Peter Crump of the University of Wisconsin CALS Computer Consulting Lab (Madison) for assistance with statistical analysis of the data.

\section{REFERENCES}

Allen, M. S. 1997. Relationship between fermentation acid production in the rumen and the requirement for physically effective fiber. J. Dairy Sci. 80:1447-1462.

Allen, M. S., B. J. Bradford, and M. Oba. 2009. The hepatic oxidation theory of the control of feed intake and its application to ruminants. J. Anim. Sci. 87:3317-3334.

AOAC. 1995. Official Methods of Analysis. 16th ed. AOAC, Arlington, VA.

Bach Knudsen, K. E. 1997. Carbohydrate and lignin contents of plant materials used in animal feeding. Anim. Feed Sci. Technol. 67:319-338.

Baker, S., and T. Herrman. 2002. Evaluating particle size. MF2051. Kansas State University Cooperative Extension Service, Manhattan.

Batajoo, K. K., and R. D. Shaver. 1994. Impact of nonfiber carbohydrate on intake, digestion, and milk production by dairy cows. J. Dairy Sci. 77:1580-1588.

Beckman, J. L., and W. P. Weiss. 2005. Nutrient digestibility of diets with different fiber to starch ratios when fed to lactating dairy cows. J. Dairy Sci. 88:1015-1023.

Bradford, B. J., and M. S. Allen. 2007. Depression in feed intake by a highly fermentable diet is related to plasma insulin concentration and insulin response to glucose infusion. J. Dairy Sci. 90:38383845 . 
Bucholtz, H. 2006. Feeding practices of high-producing herds: What can we learn? Pages 157-177 in Proc. Western Canadian Dairy Seminar, Red Deer, Alberta, Canada. University of Alberta, Edmonton, Alberta, Canada.

Dann, H. M., K. W. Cotanch, P. D. Krawczel, C. S. Mooney, R. J. Grant, and T. Eguchi. 2008. Evaluation of low-starch diets for lactating Holstein dairy cattle. J. Dairy Sci. 91(E-Suppl. 1): 530. (Abstr.)

Ferreira, G., and D. R. Mertens. 2005. Chemical and physical characteristics of corn silages and their effects on in vitro disappearance. J. Dairy Sci. 88:4414-4425.

Firkins, J. L. 1997. Effects of feeding nonforage fiber sources on site of fiber digestion. J. Dairy Sci. 80:1426-1437.

Firkins, J. L., M. L. Eastridge, N. R. St-Pierre, and S. M. Noftsger. 2001. Effects of grain variability and processing on starch utilization by lactating dairy cattle. J. Anim. Sci. 79(E- Suppl.):E218-E238.

Goeser, J. P., and D. K. Combs. 2009. An alternative method to assess 24-h ruminal in vitro neutral detergent fiber digestibility. J. Dairy Sci. 92:3833-3841.

Hall, M. B., W. H. Hoover, J. P. Jennings, and T. K. M. Webster. 1999. A method for partitioning neutral detergent-soluble carbohydrates. J. Sci. Food Agric. 79:2079-2086.

Harrison, G. A., and J. M. Tricarico. 2007. Case study: Effects of an Aspergillus oryzae containing alpha amylase on lactational performance in commercial dairy herds. Prof. Anim. Scientist 23:291-294.

Hristov, A. N., T. A. McAllister, and K. J. Cheng. 1998. Stability of exogenous polysaccharide-degrading enzymes in the rumen. Anim. Feed Sci. Technol. 76:161-168.

Hristov, A. N., J. K. Ropp, K. L. Grandeen, S. Abedi, R. P. Etter, A. Melgar, and A. E. Foley. 2005. Effect of carbohydrate source on ammonia utilization in lactating dairy cows. J. Anim. Sci. 83:408-421.

Ipharraguerre, I. R., and J. H. Clark. 2003. Soyhulls as an alternative feed for lactating dairy cows: A review. J. Dairy Sci. 86:10521073.

Ipharraguerre, I. R., R. R. Ipharraguerre, and J. H. Clark. 2002a. Performance of lactating dairy cows fed varying amounts of soyhulls as a replacement for corn grain. J. Dairy Sci. 85:2905-2912.

Ipharraguerre, I. R., Z. Shabi, J. H. Clark, and D. E. Freeman. 2002b. Ruminal fermentation and nutrient digestion by dairy cows fed varying amounts of soyhulls as a replacement for corn grain. J. Dairy Sci. 85:2890-2904.

Johnson, L., J. H. Harrison, C. Hunt, K. Shinners, C. G. Doggett, and D. Sapienza. 1999. Nutritive value of corn silage as affected by maturity and mechanical processing: A contemporary review. J. Dairy Sci. 82:2813-2825.

Jung, S., and K. Vogel. 2008. Determination of Ronozyme RumiStar Alpha-Amylase Activity in Feed and Per Se Samples. DSM Nutritional Products Ltd. Regulatory Report No. 2500706. DSM Nutritional Products Ltd., Basel, Switzerland.

Kaiser, R., and R. Shaver. 2006. Benchmarking high-producing herds. Pages 179-190 in Proc. Western Canadian Dairy Seminar, Red Deer, Alberta, Canada. University of Alberta, Edmonton, Alberta, Canada.
Klingerman, C. M., W. Hu, E. E. McDonell, M. C. Der Bedrosian, and L. Kung Jr.. 2009. An evaluation of exogenous enzymes with amylase activity for dairy cows. J. Dairy Sci. 92:1050-1059.

Kononoff, P. J., A. J. Heinrichs, and D. R. Buckmaster. 2003 Modification of the Penn State forage and total mixed ration particle separator and the effects of moisture content on its measurements. J. Dairy Sci. 86:1858-1863.

Lopes, J. C., R. D. Shaver, P. C. Hoffman, M. S. Akins, S. J. Bertics, H. Gencoglu, and J. G. Coors. 2009. Type of corn endosperm influences nutrient digestibility in lactating dairy cows. J. Dairy Sci. 92:4541-4548.

Mertens, D. R. 1987. Predicting intake and digestibility using mathematical models of ruminal function. J. Anim. Sci. 64:15481558.

National Research Council. 2001. Nutrient Requirements of Dairy Cattle. 7th rev. ed. Natl. Acad. Sci., Washington DC.

Nocek, J. E., and S. Tamminga. 1991. Site of digestion of starch in the gastrointestinal tract of dairy cows and its effects on milk yield and composition. J. Dairy Sci. 74:3598-3629.

SAS Institute. 2004. SAS/STAT 9.1 User's Guide. Version 9.1. Cary, NC.

Staples, C. R. 2007. Feeding dairy cows when corn prices are high. Pages 7-22 in Proc. 44th Florida Dairy Production Conference, Gainesville, FL. University of Florida Extension, Gainesville.

Stone, W. C. 1996. Applied topics in dairy cattle nutrition: Soyhulls as either forage or concentrate replacement. $\mathrm{PhD}$ Thesis. Cornell University, Ithaca, NY.

Taylor, C. C., and M. S. Allen. 2005. Corn grain endosperm type and brown midrib 3 corn silage: Site of digestion and ruminal digestion kinetics in lactating cows. J. Dairy Sci. 88:1413-1424.

Tricarico, J. M., J. D. Johnston, and K. A. Dawson. 2007. Dietary supplementation of ruminant diets with an Aspergillus oryzae alpha amylase. Anim. Feed Sci. Technol. 145:136-150.

Tricarico, J. M., J. D. Johnston, K. A. Dawson, K. C. Hanson, K. R. McLeod, and D. L. Harmon. 2005. The effects of an Aspergillus oryzae extract containing alpha-amylase activity on ruminal fermentation and milk production in lactating Holstein cows. Anim. Sci. 81:365-374.

Van Soest, P. J., J. B. Robertson, and B. A. Lewis. 1991. Methods for dietary fiber, neutral detergent fiber, and nonstarch polysaccharides in relation to animal nutrition. J. Dairy Sci. 74:3583-3597.

Voelker, J. A., and M. S. Allen. 2003a. Pelleted beet pulp substituted for high-moisture corn: 1. Effects on feed intake, chewing behavior, and milk production of lactating dairy cows. J. Dairy Sci. $86: 3542-3552$

Voelker, J. A., and M. S. Allen. 2003b. Pelleted beet pulp substituted for high-moisture corn: 2. Effects on digestion and ruminal digestion kinetics in lactating dairy cows. J. Dairy Sci. 86:3553-3561.

Wildman, E. E., G. M. Jones, P. E. Wagner, R. L. Boman, H. F. Troutt, and T. N. Lesch. 1982. A dairy-cow body condition scoring system and its relationship to selected production characteristics. J. Dairy Sci. 65:495-501. 